\title{
Discourse Analysis of EFL College Learners' Online Social Interaction and Attitudes towards FACEBOOK
}

\author{
Pei-Ling Yang ${ }^{1}$ \\ ${ }^{1}$ Center for General Education, Oriental Institute of Technology, New Taipei City, Taiwan \\ Correspondence: Pei-Ling Yang, 58, Sec.2, Sihchuan Rd., New Taipei City, Taiwan. Tel: 886-2-7738-0145. \\ E-mail: peiling1225@hotmail.com
}

$\begin{aligned} & \text { Received: September 26, } 2013 \quad \text { Accepted: October 17, } 2013 \quad \text { Online Published: November 24, } 2013 \\ & \text { doi:10.5539/ijel.v3n6p64 }\end{aligned}$ URL: http://dx.doi.org/10.5539/ijel.v3n6p64

\begin{abstract}
Computer-Mediated Communication (CMC) refers to communication through a computer between or among people, including synchronous and asynchronous modes. Whether in synchronous or asynchronous modes, a wealth of studies using $\mathrm{CMC}$ has reported the benefits of applying this medium to language learning. FACEBOOK is a social networking service, a form of CMC, which has attracted at least 800 million active users (Facebook, 2013). Through FACEBOOK, users could build up their own personal space, exchange messages, and participate in any online social group. From the perspective of teaching and learning, the social group could be used as a virtual classroom in which teachers and learners could exchange ideas after class to promote more independent learning and tighten social ties between teachers and learners and among learners. A large number of studies on language learners' use of CMC have been carried out; however, there is little research investigating English as a Foreign Language (EFL) learners' attitudes towards the application of FACEBOOK in a language learning context by using the method of discourse analysis. Thus, in this study, EFL learners' attitudes towards the application of FACEBOOK in a college language class and their online social interactions were investigated through the quantitative and qualitative methods. The participants, a group of college students $(n=20)$, enrolled in the English Composition class and took part in the study for one semester. Besides descriptive statistics utilized in the study, data from FACEBOOK interactions and post-interviews were analyzed through discourse analysis. The findings showed that the learners had positive attitudes towards FACEBOOK as an online learning community. Based on the findings, some implications would also be proposed to be of help to those who would like to apply FACEBOOK to an EFL context.
\end{abstract}

Keywords: CMC writing, FACEBOOK, EFL learners, social interaction

\section{Introduction}

CMC refers to communication through a computer between or among people (Herring, 1996; Levy, 1997), including synchronous and asynchronous modes. Whether in synchronous or asynchronous modes, a wealth of studies using CMC has reported the benefits of applying this medium to language learning (Blake, 2005; Chen, Belkada, \& Okamoto, 2004; Pasfield-Neofitou, 2011). In a CMC context, learners are provided with a more equitable platform for discussion (Warschauer, 1996); moreover, they interact more with each other (Al-Fadda \& Al-Yahya, 2010; Chun, 1994; Ducate \& Lomicka, 2008; Elola, 2010; Fischer, 2013; Goertler, 2009; Kern, 1995; Kuzu, 2007; Sharma, Ke, \& Xie, 2010; Warschauer, 2009; Yang, 2009). Through the interaction, learners are fostered to use more formal and complex language (Warschauer, 1996). FACEBOOK, a form of CMC, is a social networking service, which has attracted at least 800 million active users (Facebook, 2013). Through FACEBOOK, users could build up their own personal space, exchange messages, and participate in any online social group (Goertler, 2009). In a FACEBOOK-integrated learning environment, learners' learning motivation, interest, and interactions would be enhanced (Shih, 2013) and their English writing confidence would be built up as well (Yunus, Salehi, \& Chenzi, 2012).

A body of work on language learners' use of CMC has been carried out; however, there is little research investigating EFL learners' attitudes toward FACEBOOK as a virtual English writing classroom and their social interaction by using the method of discourse analysis. Therefore, this study applied Halliday's functional grammar, the social presence model proposed by Rourke, Anderson, Garrison, \& Archer (2001), and content analysis to interpret learners' perceptions of FACEBOOK for academic purposes. Social interaction is considered a significant procedure in language learning, according to Vygotskyan social-cultural theory. In the similar vein, 
learning a language refers to participation in social activities (Lantolf, 2000). Thus, social interaction is one of the major exploratory themes in the study.

From the view of functional grammar, language is used as a way to show attitudes, comments, and even the relationship between writers and readers (Halliday, 1985, 1989). Functional grammar consists of three language function analyses: ideational, interpersonal, and textual. In the study, only the interpersonal function is discussed for the purpose of investigating social interaction. One of the key characteristics in the interpersonal analysis is the use of pronouns. Pronouns show social distance and interaction between message senders and receivers. Besides the interpersonal analysis claimed by Halliday (1985), the model of social presence proposed by Rourke, Anderson, Garrison, \& Archer (2001) serves as reliable categorization to examine online interaction. Through the above analyses, the EFL learners' attitudes towards English writing on FACEBOOK were revealed and their online social interaction was also analyzed and interpreted.

With the intention to understand the implementation of FACEBOOK in college composition classes, the purpose of the study was to explore EFL learners' attitudes towards writing on FACEBOOK, their social interaction, and their word choices used to describe FACEBOOK as a virtual classroom. Therefore, this study was guided by the following four questions:

1. What are the EFL learners' attitudes towards FACEBOOK as a virtual writing classroom?

2. How would they describe FACEBOOK as a virtual writing classroom?

3. Is there any social interaction in the FACEBOOK classroom?

4. Do the EFL learners actively participate in the FACEBOOK classroom?

\section{Method}

\subsection{Research Design}

The overall research design incorporated a case study model. This study was carried out for one semester at a university in northern Taiwan. The learners in the study were taking English Writing as a compulsory course, about two 50-minute class periods on a weekly basis. Besides the traditional classroom instruction, they were asked to participate in the FACEBOOK classroom (Figure 1) after regular classes. In the classroom, each learner used his or her own FACEBOOK account to take part in the English Writing Group. Each online post and feedback was only viewed by the learners and the course instructor, not the public.

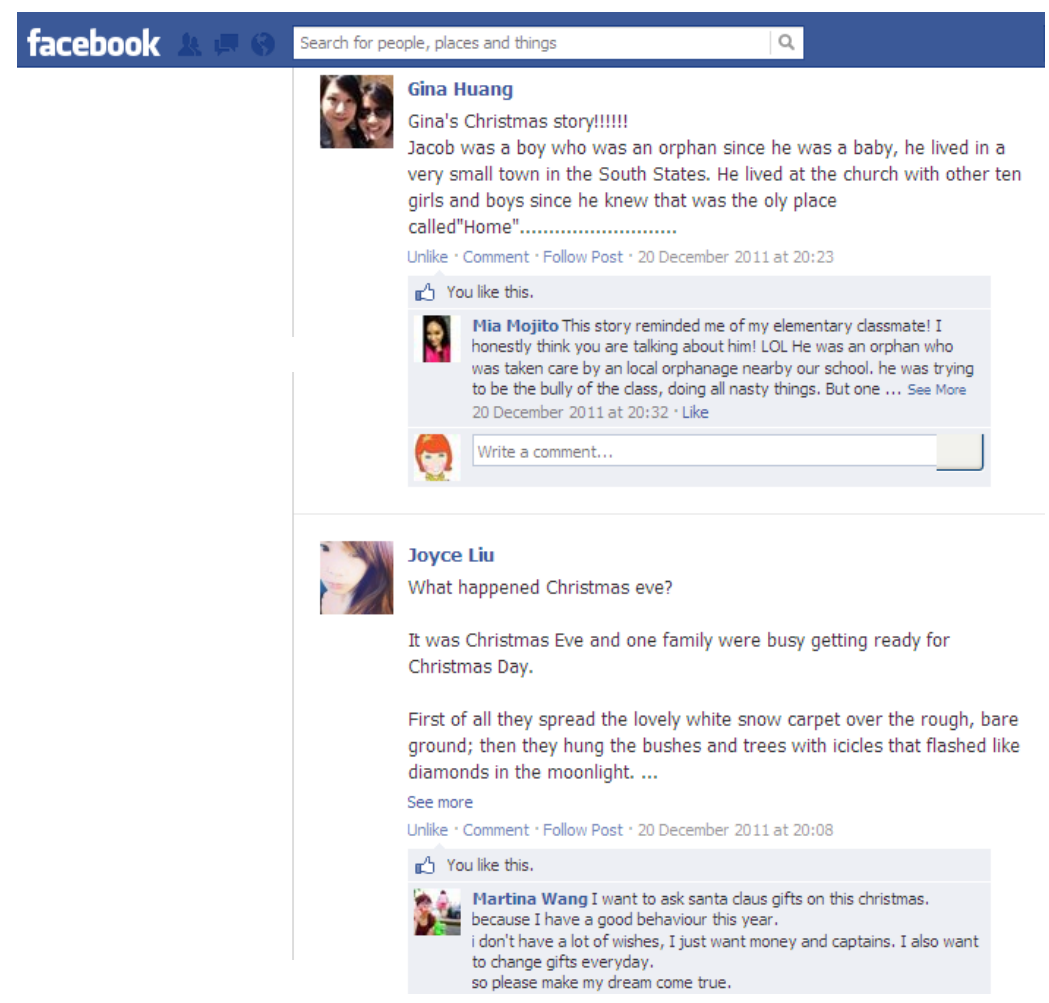

Figure 1. The FACEBOOK classroom site 


\subsection{Participants}

The participants in the study were third-year university students of the Department of Applied English of a university in northern Taiwan. They were recruited for the following reasons: (a) As third-year Applied English majors, all needed to take an English Writing course and they all had at least two years of writing training in the university, and (b) the researcher was also the instructor of this writing course. Among the twenty learners, 3 were male and 17 female, with at least 9 years of English learning experiences (from secondary school to college). They were asked to post their writing assignments online and give their peers feedback during the semester in the year of 2011. Their FACEBOOK interaction and reflection on this FACEBOOK writing group were collected as the major data for analysis.

\subsection{Data Collection Procedures}

The study was conducted during a regular two 50-minute class periods on a weekly basis. Besides attending the traditional classroom course, the twenty learners also participated in the FACEBOOK classroom. The classroom was set up as a closed group on FACEBOOK. Only the twenty learners and the instructor could have access to the writing group. At the outset of the study, all the learners reported that they had already had an FACEBOOK account. Therefore, there was no need to open a new account. Secondly, they were all asked to hand in their assignments online. In other words, their assignments were posted on FACEBOOK where they would be able to read each other's writing and to offer feedback. After the end of the semester, all the learners were asked to reflect on what they thought about the classroom in open-ended questions. The questions were all in English but attached with Chinese translation in case any misunderstanding might occur. The Chinese version of questions was also back-translated into English to ensure the validity to be achieved. Below were the reflection questions:

1. Have you used FACEBOOK before the semester?

2. Have you used FACEBOOK for academic purposes before the semester?

3. Do you enjoy FACEBOOK as a virtual classroom? Please write down the things you like and dislike about it? (At least 40 words in English)

4. Do you want to keep using the FACEBOOK group for the writing class?

5. How would you describe the FACEBOOK group for the writing class? (You may use several adjectives to describe it.)

The researcher collected learners' reflections on the FACEBOOK classroom and systematically analyzed them into several categories. Each category presented how the learners accepted FACEBOOK as a virtual classroom. Moreover, learners' online interaction was included in the data analysis, serving as the main source for interaction analysis. Viewed together, these data sources were to illustrate EFL learners' feelings about writing in the FACEBOOK classroom and their online social interaction.

\subsection{Description of the Instruments}

What they wrote about how they felt about the FACEBOOK classroom and their online interaction were collected as the major data for analysis. The learners' feedback toward the project, first of all, was examined by content analysis and discourse analysis to understand more about whether they accept the FACEBOOK for academic purposes or not. Secondly, the content of the online interaction was analyzed through Halliday's interpersonal metafunction analysis $(1985,1989)$ and the social presence model proposed by Rourke et al. (2001). Given the above findings, it was acknowledged that the learners' underlying feelings about FACEBOOK as a virtual classroom and their social interaction were well presented in the study.

\subsection{Ethical Considerations}

Before the beginning of this study, all participants were informed of the study purpose and they all agreed to involve themselves in the FACEBOOK classroom. They were also advised that they could withdraw from the study under any circumstance. The confidentiality of the participants was also ensured by not revealing their names or any personal information. Only details relevant to the study were included.

\section{Results}

In the study, the learners were asked to answer five open-ended questions regarding the FACEBOOK classroom. Given the results of the first two questions, it was acknowledged that all of the learners had used FACEBOOK before but only a few of them (20\%) had used it for academic purposes. When asked about whether they would like to continue using the FACEBOOK classroom, only two of them $(10 \%)$ reported explicit unwillingness to do so and two of them $(10 \%)$ remained neutral. However, the majority of them $(80 \%)$ had positive feelings about 
using it in the future. In the following part, the findings about the EFL learners' attitudes towards FACEBOOK as a classroom, their social interaction, and their description of the writing group on FACEBOOK were presented respectively.

The analysis was divided into three major parts: attitudes towards FACEBOOK as a virtual English writing classroom, adjective description, and social interaction. Firstly, based on the learners' reflection, their attitudes towards FACEBOOK as a virtual classroom were examined by content analysis. Secondly, the learners' description of the FACEBOOK writing classroom was systematically categorized through content analysis. Finally, in order to investigate social interaction, the learners' online posting and feedback were analyzed through Halliday's interpersonal metafunction analysis $(1985,1989)$ and the social presence model proposed by Rourke et al. (2001). Below were the analyses for each part.

\subsection{Attitudes towards FACEBOOK as a Virtual English Writing Classroom}

Analyzed through the learners' reflection, it was found that the majority (75\%) had positive attitudes towards FACEBOOK as a virtual English writing classroom (Table 1). Moreover, their good feelings about it were grouped into four main categories: convenience, mutual learning, social connection, and real-time communication.

Table 1. The EFL learners' attitudes towards FACEBOOK as a virtual classroom

\begin{tabular}{ccc}
\hline Attitudes & Frequency & Percentage \\
\hline Positive & 15 & $75 \%$ \\
Neutral & 2 & $10 \%$ \\
Negative & 3 & $15 \%$ \\
\hline
\end{tabular}

\subsubsection{Convenience}

In the study, the learners expressed their feelings about the FACEBOOK classroom. Among the positive opinions, convenience is oft-occurred in their reflection. They thought that the FACEBOOK classroom resulted in convenience to both students and teachers.

Mimi: I like it, because it is very convenient for me to upload the information from teacher, and also can finish the assignment on facebook easily.

Ruby: Yes, I enjoy FACEBOOK as a virtual classroom, because it's convenient and you can check it all the time.

Alice: Yes! I enjoy FACEBOOK as a virtual classroom. Because the facebook is so convenient. I can learn everywhere such as in the bus or when you waiting for someone.

\subsubsection{Mutual Learning}

Besides convenience, the learners reported that it was good for them to read others' writing and also to learn from them. In other words, the FACEBOOK classroom served as an open space in which every learner had a chance to learn from peers while in a traditional classroom, the opportunity for mutual learning was rare.

Weng: In the Facebook, I can see many people use the English to answer the questions. It's good to me to learn and see many English on the Facebook.

\subsubsection{Social Connection}

Not only did learning occur in the FACEBOOK classroom, but the learners felt connected to each other. Social connection was vividly shown through the learners' reflection.

Marcy: Yes, it gets the students more connected to each other also with the teacher.

Joy: It's easy to contact with other classmates.

\subsubsection{Real-Time Communication}

Apart from the above analysis, the learners thought that the FACEBOOK classroom was a place in which students could send and receive opinions from each other in no time. Thus, in this online learning context, learners could be able to express themselves without the limitation of time and space.

Curtis: Students are easy to use facebooks' advantage such as real-time communication and instant messaging. 
It's really a good platform to us.

The analysis above which was based on the answers from the reflection form revealed that the learners had fun participating in the FACEBOOK classroom and they also became closer to their classmates. Most importantly, they thought they were provided with more opportunities to learn from each other. Besides the analysis of the reflection form, the analysis of the online interaction content demonstrated that the learners complimented and encouraged their peers, creating a sense of belonging in this virtual society.

\subsection{Adjective Description}

Aside from the analyses of the learners' attitudes towards FACEBOOK as English writing classroom, adjectives were used to describe how they feel about participating in the FACEBOOK classroom. In the FACEBOOK classroom, the learners handed in assignments, posted feedback, and asked questions for one semester. Therefore, how they feel about it after the semester was expressed by adjectives. The adjectives written down by the learners were in English; there was no need to do translation. Below is the adjective description of the writing group on FACEBOOK (Table 2).

Table 2. Adjective description of the writing group on FACEBOOK

\begin{tabular}{llc}
\hline & \multicolumn{1}{c}{ Adjectives } & Frequency \\
\hline Positive & Interesting; fun & 5 \\
& Convenient; easy & 12 \\
& Special & 1 \\
& Useful & 1 \\
& Good; nice; wonderful; terrific; fabulous & 5 \\
& Enjoyable; satisfied & 1 \\
& Real-time; immediate & 5 \\
& Efficient & 1 \\
& Effective & 1 \\
& Easy & 3 \\
& Environmental friendly & 2 \\
\hline Negative & horrible & total: $\mathbf{9 0 . 2 \%}$ \\
\hline & Nervous & 1 \\
& worried & 1 \\
\hline
\end{tabular}

From the above table, it was claimed that the learners felt good about the experience of using FACEBOOK as a virtual classroom. They used "convenient," "easy," and "interesting" to describe it. The majority of adjectives (90.2\%) were positive while a few negative adjectives $(9.8 \%)$ were shown on the learners' reflection. The learners who wrote down negative adjectives were interviewed; they told the researcher that it made them nervous, worried, and pressured to log into the FACEBOOK classroom frequently. To them, it seemed that there were piles of assignments waiting for them to finish. Besides the burden, one student reported that FACEBOOK should only be used for entertainment and relaxation, not for assignments or academic purposes.

\subsection{Social Interaction}

Besides the learners' attitudes towards the FACEBOOK classroom and adjective description, their social interaction was investigated and well presented in the following part. In this virtual classroom, the learners actively participated, which could be manifested by their online posting (103 times) and feedback (136 times). Speaking of feedback, the "Like button" was pressed frequently (92 times) as a way of sending agreement to others. The "Like button" on FACEBOOK could be regarded as a sign of social interaction and nonverbal agreement. 
Furthermore, through Halliday's interpersonal metafunction analysis and the social presence model proposed by Rourke et al. (2001), social interaction between the learners could be revealed and interpreted. Analyzed from the learners' feedback in the FACEBOOK classroom, the data showed that there was interactive social presence (Table 3). Among the eight indicators, "refer to content" (22.7\%) and "agreement" (22.7\%) are the most frequently-appeared ones, followed by "complimenting" (20.5\%) and "asking questions" (18.2\%). Thus, it was acknowledged that while posting feedback, the learners would refer to what the others said previously and they would also express agreement. Moreover, offering compliments and asking questions were oft-occurred in the content of feedback. Online feedback, indeed, served as an indication of social interaction. Below are the two examples of agreement from the study data.

1. Shen: Yes, I do speak different kinds of English depending on who I'm speaking with. I noticed that when I'm skyping with my friend Ayumi, who lives in Japan, I tend to speak English with Chinese grammar because she also speaks English with Japanese grammar.

Curtis: I had similar experience just like yours. It' bad that I get used to it....

2. Gigi: According to that reason English is not my first language, how could I even avoid to speak English without Chinese logic.I do speak Chinese English very often without notice no matter talk with my American friends or friends who can speak Chinese

Shen: It's so true that we can never escape Chinese logic when we're speaking English. $>$ “ $<$ But just as your friend said, it's good English as long as we can deliver our message succesfully.

Table 3. The interactive category of social presence (Adapted from Rourke et al., 2001)

\begin{tabular}{llcl}
\hline Category & \multicolumn{1}{c}{ Indicator } & Frequency & \multicolumn{1}{c}{ Example } \\
\hline Interactive & Direct Quote & 1 & "Write down 80 words about what you think of the movie." \\
& Refer to Content & 10 & The story you wrote remind me of my elementary classmate! \\
& Appreciation & 2 & I'll never forget what you did for us. \\
Complimenting & 9 & Amazing! You're a true artist! \\
Encouraging & 1 & Your English is good. No need to worry too much. \\
Asking & 8 & What does "ding gou zhi" mean? \\
Questions & & \\
Advice/ Opinion & 3 & We need to learn English, but we can't forget our native language. \\
Agreement & 10 & I agree with you on the point that people who belong to the same \\
& & group usually share the same style.
\end{tabular}

Social interaction could also be presented by Halliday's interpersonal metafunction analysis $(1985,1989)$. Based on the interpersonal analysis, the frequency of personal pronouns was counted (Table 4). More first and second person pronouns mean that writers try to make readers feel close to each other, creating their own social community. This sense of belonging was manifested significantly by the most frequently-occurred first person pronouns $(56.9 \%)$. However, the frequency percentage of second person pronoun $(15.9 \%)$ was small, compared with that of third person pronouns (27.2\%). The main reason for the high percentage of third person pronouns was that the learners were asked to give feedback to the movie "Joy Luck Club" and Patricia Ryan's talk on TED The main characters of Joy Luck Club are female and the presenter, Patricia Ryan, is also a woman. Therefore, female third person pronoun (she/her) was used so frequently $(9.2 \%)$. To conclude, the learners used a very high percentage of first person pronouns in the study, creating a direct and face-to-face communication. Apart from the analysis of personal pronouns, the learners' initiations and responses on FACEBOOK were examined by Halliday's interpersonal function (Table 5) to discover more about their social interaction. The findings showed that there were 110 times of initiating-and-responding pairs. Among them, the majority pairs were statement-acknowledgement pairs $(94.9 \%)$, followed by question-answer $(2.9 \%)$ and offer-acceptance $(2.2 \%)$. In virtue of the FACEBOOK context, the special function, the "Like" button, regarded as acknowledgement in the study, was used most frequently. As shown in Table 4, the total "Like" acknowledge was 92 times $(71.3 \%)$ while there were 37 times (28.7\%) for written acknowledge. Given the above analyses, the social interaction was significantly presented in this study; similarly, Warschauer (2004) mentioned that "Computer-mediated 
communication combines several features that together make it a powerful new medium of human interaction (p. 5)."

Table 4. Personal pronouns used in the FACEBOOK classroom

\begin{tabular}{|c|c|c|c|c|}
\hline \multicolumn{2}{|c|}{ Personal Pronoun } & \multirow{2}{*}{$\begin{array}{c}\text { Frequency } \\
552\end{array}$} & \multirow{2}{*}{$\begin{array}{c}\text { Percentage } \\
46.3 \%\end{array}$} & \multirow{2}{*}{$\begin{array}{l}\text { Example } \\
\text { I don't think I'll see the movie tonight. } \\
\text { I have to prepare for the TOEIC exam. }\end{array}$} \\
\hline $\begin{array}{l}\text { First } \\
\text { Person }\end{array}$ & I (me) & & & \\
\hline & We (us) & 126 & $10.6 \%$ & $\begin{array}{l}\text { When we know more then we can } \\
\text { bring more peace to the world. }\end{array}$ \\
\hline $\begin{array}{l}\text { Second } \\
\text { Person }\end{array}$ & You (you) & 189 & $15.9 \%$ & $\begin{array}{l}\text { Why do you have to sacrifice yourself } \\
\text { in a relationship? }\end{array}$ \\
\hline \multirow[t]{4}{*}{$\begin{array}{l}\text { Third } \\
\text { Person }\end{array}$} & He (him) & 22 & $1.8 \%$ & $\begin{array}{l}\text { He lived at the church with other ten } \\
\text { girls and boys since he knew that was } \\
\text { the only place called "Home." }\end{array}$ \\
\hline & She (her) & 109 & $9.2 \%$ & $\begin{array}{l}\text { According to the speech she thought as } \\
\text { English goes to internationally, people } \\
\text { tend to learn English as much as } \\
\text { possible instead of their original ones. }\end{array}$ \\
\hline & It (it) & 102 & $8.6 \%$ & The daughter was reluctance to eat it. \\
\hline & They (Them) & 91 & $7.6 \%$ & $\begin{array}{l}\text { And mirroring them is indeed an } \\
\text { effective way to win recognition. }\end{array}$ \\
\hline
\end{tabular}

Table 5. Percentage of frequency of speech function pairs (Adapted from Halliday, 1985)

\begin{tabular}{|c|c|c|c|c|c|}
\hline \multirow{2}{*}{\multicolumn{2}{|c|}{$\begin{array}{l}\text { Initiating Speech } \\
\text { Function }\end{array}$}} & \multicolumn{4}{|c|}{ Responding Speech Function } \\
\hline & & \multirow{2}{*}{\begin{tabular}{r|} 
Supporting \\
Acceptance
\end{tabular}} & \multicolumn{3}{|c|}{ Confronting } \\
\hline Offer & $2.9 \%$ & & $2.2 \%$ & Rejection & 0 \\
\hline Command & 0 & Compliance & 0 & Refusal & 0 \\
\hline Statement & $93.2 \%$ & $\begin{array}{c}\text { Acknowledgement } \\
\text { (The "Like" button: } 71.3 \% \text { ) } \\
\text { (Written text: } 28.7 \% \text { ) }\end{array}$ & $94.9 \%$ & Contradiction & 0 \\
\hline Question & $3.9 \%$ & Answer & $2.9 \%$ & Disclaimer & 0 \\
\hline
\end{tabular}

In the study, it was obvious to see social interaction among the EFL learners. Once they initiated speech, the others responded, especially in a supporting manner. They frequently offered acknowledgement to their peers (94.9\%), particularly using the "Like" function on FACEBOOK. In short, the learners, in this CMC context, not only have more chances to use the target language but take part in this virtual social network, sharing their opinions and encouraging their peers. CMC indeed strengthens the connection between learners. Learners, therefore, on one hand, practice the target language; on the other hand, they develop social interaction skills and gain support and acknowledgement from each other.

\section{Discussion and Implications of Findings}

The findings of this study reveal that the majority of the learners (75\%) have positive attitudes towards the FACEBOOK classroom, grouped into four categories: convenience, mutual learning, social connection, and real-time communication. In light of these, it is claimed that the EFL learners think FACEBOOK is a convenient platform where they could learn from each other, socialize with each other, and communicate with each other immediately. Apart from their good feelings about it, they also presented highly social interaction. Social interaction is manifested by Halliday's interpersonal metafunction analysis $(1985,1989)$ and the social presence model proposed by Rourke et al. (2001). The most frequently-occurred indicators of social presence are "refer to content" $(22.7 \%)$, "agreement" $(22.7 \%)$, and "complimenting" $(20.5 \%)$. In the study, the learners actively 
participate in the FACEBOOK classroom, handing in assignments and posting feedback. Furthermore, they socially interact with each other, through expressing agreement and making compliments to their peers.

Besides the social presence model, the use of personal pronouns, one of the key characteristics of Halliday's interpersonal analysis, serves as a sign of social interaction. In the study, first person pronouns occur most frequently $(56.9 \%)$, creating direct and personal communication. Moreover, the learners frequently offer acknowledgement to their peers $(94.9 \%)$, particularly using the "Like" function on FACEBOOK. Social interaction is acknowledged in this study; in the similar vein, many empirical studies claim (Kamhi-Stein, 2000; McPherson \& Nunes, 2004; Shih, 2013; Trajtemberg \& Androula, 2011; Warschauer, 2009) that the learners' social interaction has improved and mutual support has also been gained through CMC contexts. The majority $(80 \%)$ reported that they would like to continue using FACEBOOK for academic purposes. Moreover, they used positive adjectives $(90.2 \%)$ to describe the writing group on FACEBOOK. To sum up, most learners have positive feelings about the FACEBOOK classroom and the presence of social interaction is obviously shown in the study.

Based on the study findings, researchers, in future studies, could take learner's workload and private life into consideration, making more and more learners joyfully participate in this kind of learning without feeling something negative or being much pressured. It is hoped that the findings and conclusions shed some light on the application of FACEBOOK in a composition class and it would be of help to those language teachers who would like to arouse learners' participation and promote more positive interaction between or among learners.

\section{References}

Al-Fadda, H., \& Al-Yahya, M. (2010). Using web blogs as a tool to encourage collaboration in higher education. US-China Education Review, 7(7), 100-106.

Blake, R. J. (2005). Bimodal CMC: The Glue of Language Learning at a Distance. CALICO Journal, 22(3).

Chen, J., Belkada, S., \& Okamoto, T. (2004). How a web-based course facilitates acquisition of English for academic purposes. Language Learning \& Technology, 8(2).

Chun, D. (1994). Using Computer Networking to Facilitate the Acquisition of Interactive Competence. System: An International Journal of Educational Technology and Applied Linguistics, 22(1), 17-30. http://dx.doi.org/10.1016/0346-251X(94)90037-X

Ducate, L., \& Lomicka, L. (2008). Adventures in the blogosphere: From blog readers to blog writers. Computer Assisted Language Learning, 21(1), 9-28. http://dx.doi.org/10.1080/09588220701865474

Elola, I., \& Oskoz, A. (2010). Collaborative writing: Fostering foreign language and writing conventions development. Language Learning \& Technology, 14(3), 51-71.

Facebook. (2013). Statistics: Active users on Facebook. Retrieved October 16, 2013, from http://newsroom.fb.com/Key-Facts

Fischer, R. (2013). A conceptual overview of the history of the CALICO journal: The phases of CALL. CALICO Journal, 30(1-9). http://dx.doi.org/10.11139/cj.30.1.1-9

Goertler, S. (2009). Using Computer-Mediated Communication (CMC) in Language Teaching. ProQuest Education Journals, 42(1), 74-87.

Halliday, M. A. K. (1985). An introduction to functional grammar. London: Edward Arnold Ltd.

Halliday, M. A. K. (1989). Spoken and written language. Oxford: Oxford University Press.

Herring, S. C. (Ed.). (1996). Computer-mediated communication: Linguistic, social, and cross-cultural perspectives. Amsterdam: John Benjamins.

Kamhi-Stein, L. D. (2000). Integrating computer-mediated communication tools into practicum. In K. E. Johnson (Ed.), Teacher education: Case studies in TESOL practice (pp. 119-136). Alexandria, VA: TESOL.

Kern, R. G. (1995). Restructuring classroom interaction with networked computers: Effects on quantity and characteristics of language production. The Modern Language Journal, 79(4), 457-478. http://dx.doi.org/10.1111/j.1540-4781.1995.tb05445.x

Kuzu, A. (2007). Views of pre-service teachers on blog use for instruction and social interaction. Turkish Online Journal of Distance Education, 8(3), 34-52.

Lantolf, J. P. (2000). Sociocultural theory and second language learning. Oxford, UK: Oxford University Press. 
Levy, M. (1997). Computer-assisted Language Learning: Context and Conceptualization. New York: Oxford University Press. http://dx.doi.org/10.1080/0958822970100103

McPherson, M., \& Nunes, M. B. (2004). The failure of a virtual social space (VSS) designed to create a learning community: Lessons learned. British Journal of Educational Technology, 35(3), 305-321. http://dx.doi.org/10.1111/j.0007-1013.2004.00391.x

Pasfield-Neofitou, S. (2011). Online domains of language use: Second language learners' experiences of virtual community and foreignness. Language Learning \& Technology, 15(2).

Rourke, L., Anderson, T., Garrison, D. R., \& Archer, W. (2001). Assessing social presence in asynchronous text-based computer conferencing. Journal of Distance Education, 14(2).

Sharma, P., Ke, F.-F., \& Xie, Y. (2010). The Effects of Peer-Interaction Styles in Team Blogs on Students' Cognitive Thinking and Blog Participation. Journal of Educational Computing Research, 42(4), 459-479. http://dx.doi.org/10.2190/EC.42.4.f

Shih, R.-C. (2013). Effect of using facebook to assist English for business communication course instruction. TOJET: The Turkish Online Journal of Educational Technology, 12(1), 52-59.

Trajtemberg, C., \& Androula, Y. (2011). Weblogs: A tool for EFL interaction, expression, and self-evaulation. ELT Journal, 65(4), 437-445. http://dx.doi.org/10.1093/elt/ccr015

Warschauer, M. (1996). Comparing Face-to-Face and Electronic Discussion in the Second Language Classroom. CALICO Journal, 13(2), 7-26.

Warschauer, M. (2009). Electronic literacies: Language, culture, and power in online education. Mahwah, NJ: Lawrence Erlbaum Associates, Inc.

Yang, S.-H. (2009). Using blogs to enhance critical reflection and community of practice. Educational Technology \& Society, 12(2), 11-23.

Yunus, M. M., Salehi, H., \& Chenzi, C. (2012). Integrating social networking tools into ESL writing classroom: Strengths and weaknesses. English Language Teaching, 5(8), 42-48. http://dx.doi.org/10.5539/elt.v5n8p42

\section{Copyrights}

Copyright for this article is retained by the author(s), with first publication rights granted to the journal.

This is an open-access article distributed under the terms and conditions of the Creative Commons Attribution license (http://creativecommons.org/licenses/by/3.0/). 